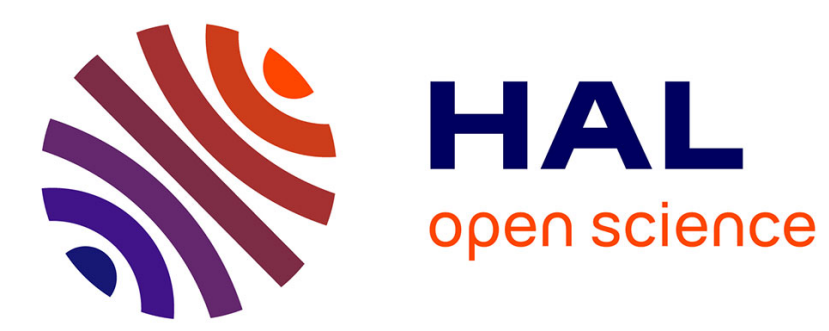

\title{
Initial spare parts supply of an orbital system
}

\author{
François Pérès, Jean-Christophe Grenouilleau
}

\section{To cite this version:}

François Pérès, Jean-Christophe Grenouilleau. Initial spare parts supply of an orbital system. Aircraft Engineering and Aerospace Technology, 2002, vol.74 (n³), pp.252-262. 10.1108/00022660210427431 . hal-01296530

\section{HAL Id: hal-01296530 \\ https://hal.science/hal-01296530}

Submitted on 1 Apr 2016

HAL is a multi-disciplinary open access archive for the deposit and dissemination of scientific research documents, whether they are published or not. The documents may come from teaching and research institutions in France or abroad, or from public or private research centers.
L'archive ouverte pluridisciplinaire HAL, est destinée au dépôt et à la diffusion de documents scientifiques de niveau recherche, publiés ou non, émanant des établissements d'enseignement et de recherche français ou étrangers, des laboratoires publics ou privés. 


\section{Open Archive TOULOUSE Archive Ouverte (OATAO)}

OATAO is an open access repository that collects the work of Toulouse researchers and makes it freely available over the web where possible.

This is an author-deposited version published in : http://oatao.univ-toulouse.fr/ Eprints ID : 10341

To link to this article : DOI : 10.1108/00022660210427431

URL : http://dx.doi.org/10.1108/00022660210427431

To cite this version : Pérès, François and Grenouilleau, Jean-Christophe Initial spare parts supply of an orbital system. (2002) Aircraft

Engineering and Aerospace Technology, vol.74 ( $\mathrm{n}^{\circ} 3$ ). pp.252-262. ISSN $0002-2667$

Any correspondance concerning this service should be sent to the repository administrator: staff-oatao@ listes-diff.inp-toulouse.fr 


\section{Initial spare parts supply of an orbital system}

\author{
François Pérès and \\ Fean-Christophe Grenouilleau
}

\section{The authors}

François Pérès is Assistant Professor, Laboratoire Productique Logistique, Ecole Centrale Paris, Grande Voie des Vignes, 92295 Châtenay-Malabry cedex, France Jean-Christophe Grenouilleau is Project Manager, European Space Agency, DIMSM-EOI, Delft, Netherlands

\section{Keywords}

Risk, Supply chain

\section{Abstract}

This article presents a method of management of the initial spare parts supply. This generic problem is of particular interest in certain systems in which the difficulty of accessibility or the life cycle duration constitute risks tied to the possible depletion of the spare parts stock. In this paper we consider the spatial context. After having commented on the particularities of the management of the spare parts supply of a space station, we propose a method based on the minimization of the risk of postponement of a maintenance operation. Finally, an application to the Columbus laboratory of the International Space Station is presented.

\section{Introduction}

Among the resources which are necessary to achieve maintenance tasks by replacement or repair, the spare parts take a very specific place due to the potential impact of their unavailability. For this reason, the teams which are involved in the preparation of the operation phase pay particular attention to the management of their supply. Defined in accordance with the maintenance policy, the supply management strategy mainly determined the range of spare elements, their mode of supply, as well as their geographical dispatch. Such a problem is delicate to approach in practice because of the interaction between numerous fields in the elaboration of a solution. This paper is the first part of a two-part study.

Before developing a model of spare parts supply taking into account the logistic chain, which will be the object of a future study, we introduce here a management method to control the risk related to the supply needed to cover the initial operating phase. The dreaded event (i.e. the event that the system user does not want to occur) concerns the postponement of a maintenance task because of the unavailability of a corresponding spare part. We therefore propose to quantify the risk associated with the choice of a given supply strategy. At the time of initial supply, the key parameter is the quantity to be supplied. The general problem being thus simplified, we propose the use of a classic optimisation technique to minimize the risks linked with supply management. The results may then serve as reference to aid supply negotiations.

This work is divided into three parts.

We begin by presenting the supply of spare parts in a spatial? context. After having succinctly described the elements of an orbital system, we characterize the particularities of such a system likely to influence the management of supply. A brief state of the art of the field is proposed. We then develop a method of evaluation of the initial supply. In order to do this, we introduce the notion of the risk of postponement of a maintenance task which we seek to minimize by the identification of the probability of postponement and of the gravity of the consequences related to the realization of the dreaded event. Finally, we propose an application of the method to the calculation of 
the amount of initial supply needed for the Columbus lab.

\section{Spare parts supply of an orbital station}

\subsection{Structure of a space system}

A spatial station system is generally defined by many interacting blocks called segments

(Figure 1):

- a Flight segment (A), which includes the orbital infrastructure, the crew as well as the communication means;

- a Ground segment (B), which includes the infrastructure and the means necessary to monitor the flight segment (control and communication centres), the industrial structure that allows the support of the operation as well as the infrastructure dedicated to users (preparation units of the elements to be launched and operated);

- a Transportation segment (C) which allows the transport of the crew, the results of experiments, the necessary resources and other failing elements between the station and the ground. It includes the launchers, the cargo vehicles, the infrastructures of launch and eventually return.

\subsection{Influence of the space context on the management of supply}

The need for spare parts

The feedback of previous experience concerning the maintenance of spatial systems (and consequently the supply of spare parts), is limited and the rare data collected constitutes an estimation to be taken with precaution because the systems and equipments developed are most frequently unique. In the preliminary phases, then, one must frequently resort to analogies with past programs in order to evaluate the needs in terms of replacement. Several works have estimated the needs of an orbital station in this way. A conservative estimate based on experience indicates that the needs in terms of spare elements represents annually 5 per cent of the total mass of the system. However, this depends on the level of repair that is opted for. A rather low level of repair (i.e. repairing as many elements as possible, even down to the most basic) requires more tools and higher skills but, in return a lower mass at the time of restocking.

Figure 1 Components of a spatial system

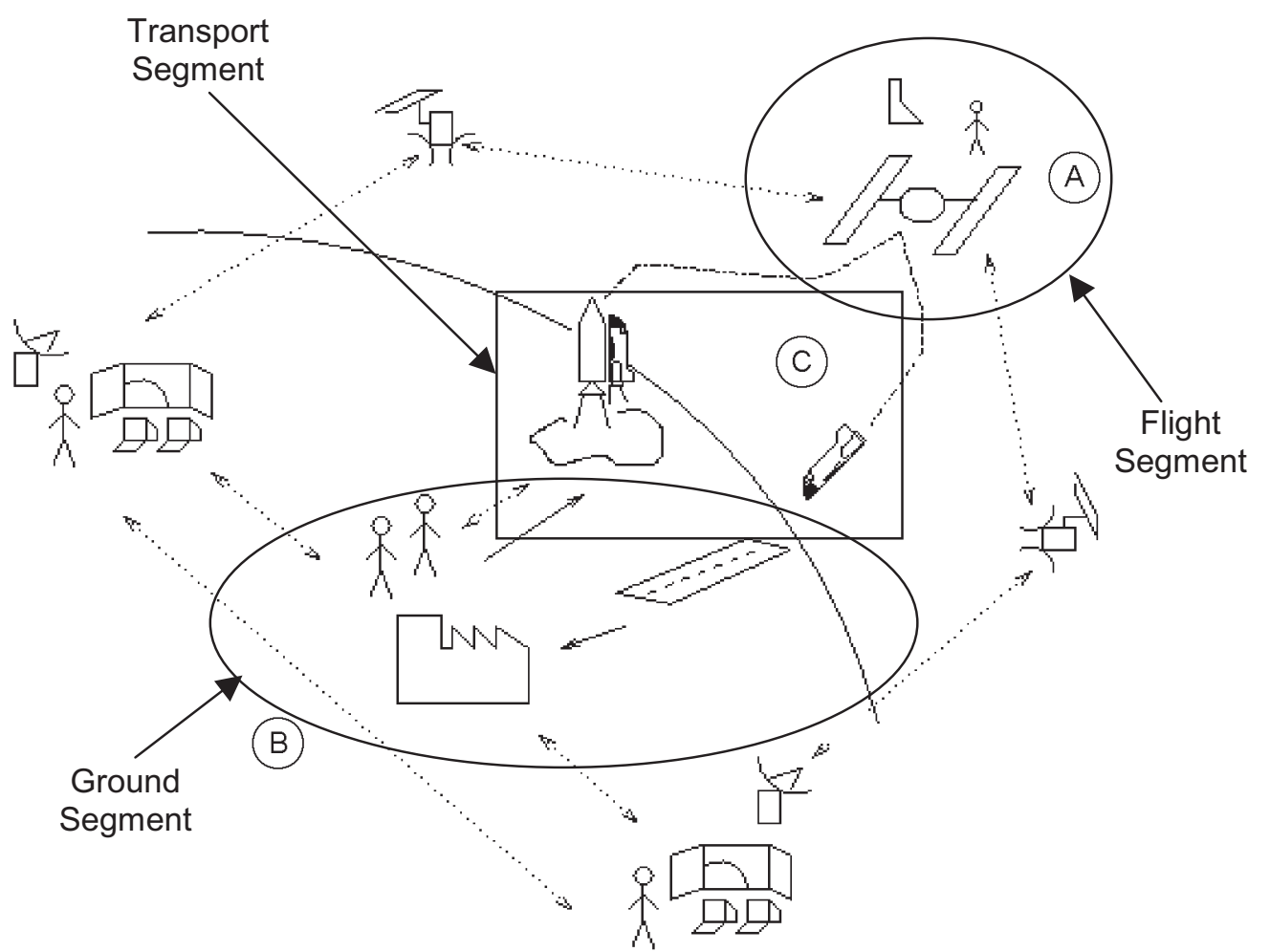


The stock

They are organized in what we define as stock echelons which means that the place of storage can be either on the ground (in the launch area or at the manufacturer's) or in orbit. One must keep in mind that storage on board an orbital space station is very much constrained in terms of available space, which has been confirmed by the Russian experience. Even though volume is limited, this is not the only hindrance to storage in the station. Let us note that the Apollo missions gave up on storing elements on board lunar modules because of the lack of knowledge about effects of radiation and space environment on the material. To replace a failing element with another whose condition could not be guaranteed was judged too risky and the adopted solution was then to specify early in the design phase the element with higher reliability. Concerning the ground stock, the geographic distribution may be very diverse: The elements could be stored at the user's base, could stay in a centralized depot at the manufacturer's, or again, be distributed between the two. The stock may concern goods at diverse levels of nomenclature (spare elements, repair items).

\section{The elements to be supplied}

Only a limited number of industrials are concerned for a very small volume and a very high cost. Very often the development and manufacturing times are very long. Because of the manufacturing lead time constraints, the supply of elements needs to be performed at the same pace as the manufacturing in order for the spare elements to be available when the system is started. Moreover, the rapid evolution of the market associated with a considerable time required to design the system often implies that many elements will be obsolete by the end of the preliminary conception phase.

\section{The repairs}

As far as repairs in orbit are concerned, the main constraint is the astronaut's qualification. Often, one makes the hypothesis that the low level repairs (e.g. a welding) are too complex and their quality too uncertain to be performed on board. Thus, the replacements are more generally performed by a total exchange of Orbit Replaceable Units (ORU). When a failing element is brought back from orbit, it is generally restored into its original condition. Indeed, because returns for repair are rare, the elements are often totally dismantled and inspected to collect as much information as possible. The cost of a repaired element in the case of the Space Lab laboratory reaches between 70 and 75 per cent of the cost of a new element, which means a gain of 25 to 30 per cent compared to the cost of a new element. However, this gain could be greatly diminished by the cost of shuttle return transport.

\section{The transport}

The frequency of transport (90 days for the International Space Station) is the fruit of a compromise between the fuel needs of the station, the load capacity of the space shuttle and takes into account a margin of security in case a restocking cannot be done. Shuttle launching data indicate that the major reason for postponement of a launch is of a meteorological nature. One complex transport problem in the context of space flight, is the existence of a lead time for loading. Because of the complexity of the evaluation process involved in the loading of space shuttles, the possibility of modifying the composition of the supply to be loaded is improbable. The continuous operations concept, such as the one envisaged for the ISS, poses serious difficulties when an urgent demand for supply is necessary. The potential impact on the planning of several flights, as well as the international aspect of the operations necessitates considering a mechanism of priorities (Blagov, 1993). Furthermore, because of the analyses of the required load, (among others the determination of the centre of gravity and moments of inertia), modifications are progressively impossible depending on the weight of elements to be added or withdrawn from the cargo.

\section{The tests}

The state of onboard systems of a space system is controlled almost permanently by means of the telemetry and reports carried out by the astronauts. Consequently, failures are immediately communicated. The passive redundancies and the stored elements pose, nevertheless, some difficulties. Theoretically, the periodical test of elements increases the probability of failure. It is necessary, then, to arbitrate between the risk of keeping an element which is potentially out of order and the risk of causing its failure during the test. 


\subsection{Supply management of an orbital station: state of the art}

The numerous works treating the management of spare parts supply in a wide variety of industrial contexts attests to its topicality. (Grenouilleau, 1999), (Guide and Srivastava, 1997). We propose a review of the models which have been proposed for the selection and management of methods of spare part supply (spare parts supplying modes) in the context of manned space flights.

The request for replacement parts considered in the models comes from failures, the coming due of preventive maintenance, and expiry of old parts. Most models only consider failures as a source of request for spare parts. The failure is always of cataleptic type and the failing performance of the part in use is not taken into consideration. The general hypothesis is that the rate of occurrence of failures is constant, which simplifies the analytic resolution of the problem - the number of requests, then, would follow a Poisson process. In any real situation, however, the renewal process is more complicated to establish (Pérès, 1996). Sepehry-Fard as well as Knezevic discuss the problems related to the application of this choice (which choice) (Sepehry-Fard and Coulthard, 1995b), (Sepehry-Fard and Coulthard, 1995a), (Sepehry-Fard and Coulthard, 1995c), (Knezevic, 1995b). We observe, then, that it is Weibull's law that is preferred, even though, paradoxically, the lack of necessary data in the use of this law often leads to return to an exponential law. The average request for a spare part may also fluctuate on the considered horizon. A dutycycle is often attributed to it (Bream, 1993). Preventive requests are generally absent in analytic models. Consequently, these requests must be sometimes taken into consideration after having run the model (Erno, 1979). The same comments can be made about the requests due to discard of old parts. While it can be noticed that the analytic treatment of these requests is complex, the models based on simulation enable the consideration of not only preventive maintenance, but also the postponement of preventive replacements in case an unexpected failure would occur before the date of expiry (Nyen, 1991). Several models consider a rate of discard for reasons of poor maintenance (Bream, 1993), (Dejulio and Leet, 1988), (McCauley, 1997). The failure of idle parts, however, seem not to be dealt with

The stocking of spare parts is, in the most simple situation, considered uniquely on one echelon (let us recall that a stock echelon, stands for a place of storage which may be either on the ground or in orbit). Often, it implicitly refers to stock in orbit. Even though most authors discuss stock constraints, they are implemented in few models. Schwaab (Schwaab, 1991) and Knezevic (Knezevic, 1995a) consider the calculation of the quantity of parts which must be stocked in orbit. They both propose a mathematic formula of knapsack type under diverse constraints (volume, mass). Schwaab's model is a particular case of the more general model of Kline and Sherbrooke (Kline and Sherbrooke, 1991). In their model, the authors take into account a multi-echelon structure (ground, orbit) and consider also the nomenclature (assembled elements, subelements, individual pieces) of stored spare parts.

Most models assume that the stored part is of the same level of nomenclature as the failed part. The resolution is, however, more difficult when the divers echelons and levels of nomenclature are considered. It is not surprising, then to observe the predominance of the use of simulation models.

The simplest supply is the one in which we consider that the parts are not repairable. In this case, the parts are replaced at the nearest opportunity and the failed parts are discarded. In the majority of cases, the substituted part is identical to the one which has to be discarded. Let us mention the Bream's model (Bream, 1993) which takes into account the improvement of the system by the new spare parts but which does not seem to use it in an explicit manner. The duration of replacement of the failed part in orbit is often neglected (Kline and Sherbrooke, 1993), (Sherbrooke, 1992), (Erno, 1979). In several models, the replacement takes place within either a duration of constant value or of exponential distribution. Considering the returns for repair makes the problem more complicated. Sherbrooke and Kline propose in (Kline and Sherbrooke, 1991) and (Sherbrooke, 1992) an analytic formulation based on the METRIC model which they initially proposed in 1968. It can be noted that simulation models generally take into account the repair chain. The failed parts are always considered 
as repairable or likely to be discarded, the latter being represented by a probability. The treatment of requests may be of equal importance (which is most common) or they may be put into a queuing system with priorities. Dejulio in (Dejulio and Furlong, 1988) and Knezevic, 1995a) consider classes of criticality. The Logistics Simulation Model (LSM) which is used by the European Space Agency, introduces a similar concept based on a loading priority (Nyen91]. The loading is subject to revision if the situation permits. The capacity for repair is most often assumed to be unlimited in the majority of models. Consequently, the problems of queuing systems are not explicitly considered. The work of Bullington et al. (Bullington et al., 1995) which aims at determining the repair priorities for the parts of the space shuttle can be mentioned. When it is not possible to respond immediately to the request for supply, cannibalisation of parts is sometimes considered. This strategy consists in using a working part on a sub-system to replace an other one of identical nature whose failure prevents the good running of a sub-system considered as more important with respect to the mission.. Sherbrooke in (Sherbrooke, 1992) and Shishko in (Shishko, 1990) take into account this possibility. Cannibalisations give good results in terms of performance if they are not considered from the beginning as a policy. On the other hand, if they are foreseen but not implemented, the performance of the system is lowered. Similarly, it is possible to use parts not initially planned for the element which requires it. The sharing of spare parts is also considered in (Sherbrooke, 1992) and (Kline and Sherbrooke, 1993).

The transport (of supplies) for an orbital station is particular in that it is not continuous and is carried out at precise, periodic instances. Some authors, notably Knezevic (Knezevic, 1995b) and Schwaab (Schwaab, 1991) simplify the problem and do not consider the concept of discreet supply. In the other cases, the supply strategy always takes into account the periodic nature of the transport. This periodicity may be deterministic or subject to statistical fluctuation. The models actually used by the ESA (Nyen and Digernes, 1991), (Passaro et al., 1999) and NASA (Constanzi, 1996) take into account the time and capacity loading limits. The models most often consider that the quality of the spare parts carried to the space station is not diminished by the transport.

The model used by the ESA, however, takes into account a maximum number of cycles before discard. The length of the flight may be considered as instantaneous or be represented by a constant duration. The parts supplied are either used immediately or they complete the orbital stock.

\section{Methodology of evaluation of the initial supply}

\subsection{Risks related to the initial supply}

Initial supply entails the decisions about which spare parts to procure, and the stocking of them in a quantity sufficient to cover the needs of the period of initial operation of the system.

Several factors support the purchase of spare parts at the same time as start up of the production phase of the main system. In particular, we note:

- the length of time it takes to make certain parts requiring the fabrication to be started sufficiently in advance.

- the commercial unavailability of certain parts even before the initial start up of the system;

- the unavailability of industrial competence and production process due to very small series;

- economisation by buying in bulk where elements of the system and their spare parts are purchased at the same time.

In spite of these good reasons for obtaining spare parts before operation, important uncertainties remain regarding the number of possible failures as well as their time of occurrence. Decisions about the quantity and type of parts needed are made difficult by the presence of these uncertainties. One can imagine that there is a risk whose major consequence is the postponement of maintenance tasks. We call this an "Undesirable Event". At the time of initial procurement, the choice depends as much on the range of parts (which ones to choose?) as on the quantity to be supplied. In our paper, the procurement in itself is considered safe: the parts ordered are guaranteed to be delivered, without fault and at the required time.

According to Desroches (Desroches, 1995): the risk is associated with the 
perception of a dangerous situation, defined by the pair $(p, g)$ where $p$ is the probability of the occurrence of an Event $\mathrm{E}$ and $\mathrm{g}$ is the seriousness of the consequences or the damage consecutive to the carrying out of this event E.

Let us consider a system with $\mathrm{n}$ replaceable elements. Given Xi, an integer representing the quantity supplied of an element $\mathrm{Ei}$. $\mathrm{Xi}$ is such that $0 \leq X_{i} \leq$ Smax where Smax is the maximum reasonable quantity envisaged. $\bar{X}_{i}$, the "undesirable event", corresponds to an insufficient quantity supplied. We consider the period of initial supply and describe the risk linked with postponement of a maintenance task when $X_{i}$ spare parts have been supplied:

$$
\mathrm{R}\left(\bar{X}_{i}\right)=\operatorname{Pr}\left(\bar{X}_{i}\right) \cdot \operatorname{Gr}\left(\bar{X}_{i}\right)
$$

where $\mathrm{R}\left(\bar{X}_{i}\right)$ is the level of average risk associated with the supply of an insufficient quantity $X_{i}$ of spare parts for the element $i$; $\operatorname{Pr}\left(\bar{X}_{i}\right)$ represents the probability of the occurrence of the undesirable event and depends on $X_{i} ; \operatorname{Gr}\left(\bar{X}_{i}\right)$ represents the seriousness of the consequences in the case of an undesirable event.

If we consider now a possible initial supply $\mathrm{k}$ concerning the ensemble of $\mathrm{n}$ replaceable parts of the system, we obtain a vector which is written $X_{k}=\left[X_{k, 1}, X_{k, 2}, \ldots, X_{k, n}\right]$ where $X_{k, j}$ represents the quantity supplied for the element $\mathrm{i}$ in the strategy $k$. We consider that the level of risk associated with the supply of $n$ elements is the sum of the individual risks related to the supply of each element:

$$
R\left(\bar{X}_{k}\right)=\sum_{i=1}^{n} R\left(\bar{X}_{i}\right)
$$

\subsection{Probability of postponement of a maintenance task}

In the framework of this paper we do not consider the possibility of restocking during the operational phase. Thus the probability that the element be repairable depends only on the stock already available on the ground. Under these hypothesis, the renewal process is a Poisson process with parameter $\lambda_{\mathrm{i}}$. The probability that a maintenance task be postponed is then simply given by:

$$
\operatorname{Pr}\left(\bar{X}_{i}\right)=\sum_{j=X_{i+1}}^{\infty} \exp ^{-\lambda_{i} \cdot t} \cdot \frac{\left(\lambda . T_{i}\right)^{i}}{i !}
$$

Where $X_{i}$ is the quantity supplied in stock for the element $E_{i}, \lambda i$ is the failure rate of the element $E_{i}$, and $T_{i}$ is the horizon of supply considered as identical for each element. The Poisson approximation gives an inferior limit on $\operatorname{Pr}\left(\bar{X}_{i}\right)$. In fact, taking into account delays in supply, we logically observe:

- a smaller number of cases of renewal, the element having to wait in order to be put back into service from a state of failure;

- a probability of remaining in the state of failure considerably longer.

\subsection{Evaluation of the consequences of a postponement}

We consider now the ensemble of functions $\left\{\mathrm{F}_{1}, \mathrm{~F}_{2}, \ldots, \mathrm{F}_{\mathrm{j}}\right\}$ assured by the preceding system. Knowing that the failure of a element affects the system to varying degrees, we consider that the seriousness of the consequences of a delay in its replacement is directly related to the element's importance in the total system. We must, then, first determine a scale measuring the gravity of the impact of failures on the system and attribute to the element the corresponding level of criticality.

Generally speaking, the seriousness of the consequences may be defined as being the measure of the relative influence on the system. In the framework of this paper and with the agreement of the engineers, the criteria chosen to represent this impact is the level of deterioration of the system's running.

In order to permit the ranking of the task postponement we refer to a distribution according to classes of gravity (Table I). This distribution covers a range of consequences going from the absence of notable effect to incapacity to continue operation. We consider that the economic consequences are implicit in the classification.

We consider here that the levels of gravity remain constant with time. (?meaning) However, it can be noted that this measure of consequences also possesses a dynamic: the

Table I Classes of failure gravity

\begin{tabular}{lll}
\hline Class & \multicolumn{1}{c}{ Heading } & \multicolumn{1}{c}{ Description } \\
\hline $\mathbf{1}$ & Without effect & Absence of notable effect \\
$\mathbf{2}$ & Minor & Minor degradation of operations \\
$\mathbf{3}$ & Major & Moderate degradation of operations \\
$\mathbf{4}$ & Critical & Important degradation of operations \\
$\mathbf{5}$ & Catastrophic & Incapacity to continue operation \\
\hline
\end{tabular}


consequence of a failure of an element initially considered as catastrophic, may later prove to be minor.

The second step in estimating the gravity of a maintenance task delay necessitates being able to associate the consequence of a failure with one of the previously identified classes. This can be done by determining the importance of the element within the system. We have envisaged a qualitative approach, which consists in considering a failure of an element of the system in order to attribute to it one of the predefined levels of gravity. To this end, we have developed a tree of allocation of gravity (Cf. Figure 2).

\subsection{Mathematic application}

\subsubsection{Formulation of the problem}

When the probability and gravity associated with the delay of a maintenance task have been evaluated, it is possible to quantify the level of risk associated with a supply strategy. Let us recall that we consider it reasonable to imagine that the risk associated with a strategy regarding $n$ elements is equal to the sum of the individual risk of each of the elements. We can then provide a mathematic formulation of the problem of available budget allocation. It refers to the classic combinatorial optimisation problem, belonging to the family of problems called "Knapsack" (Minoux, 1983), (Kedad-Sidhoum, 1997). We note as $P$ the problem to be solved and write:

$$
(P)\left\{\begin{array}{l}
\min \cdot \sum_{i} R\left(\bar{X}_{i}\right) \\
\sum_{i} C_{i} \cdot X_{i} \leq B
\end{array}\right.
$$

In this chapter we describe the function of risk $\mathrm{R}\left(\bar{X}_{i}\right)$ where the only variable taken into account is the quantity supplied $X_{i}$. The only constraint that we consider is budgetary, noted as B. We can, of course, ultimately envisage additional constraints such as the volume or the mass. Ci represents the cost of the spare part $i$ and is regarded as a positive integer. We consider the description of the problem under the form of a graph presented in (Minoux, 1983). We use the graph $\mathrm{G}=$ [U, X] (Figure 3) where:

- $X$ consists of an initial node and of nq nodes where $n$ is the number of elements and $\mathrm{q}$ is the maximum quantity of spare parts for $X_{i}$, represented as $\mathrm{Si}$, max. To each node corresponds a couple $(E, i)$ where $\mathrm{E}$ is the necessary budget;

- U consists of the ensemble of arcs between the nodes and the length is therefore given as $\mathrm{R}\left(\bar{X}_{i}\right)$.

We observe that every circuit between the initial and terminal nodes is a potential solution. We define, then, the following

Figure 2 Tree of allocation of level of gravity

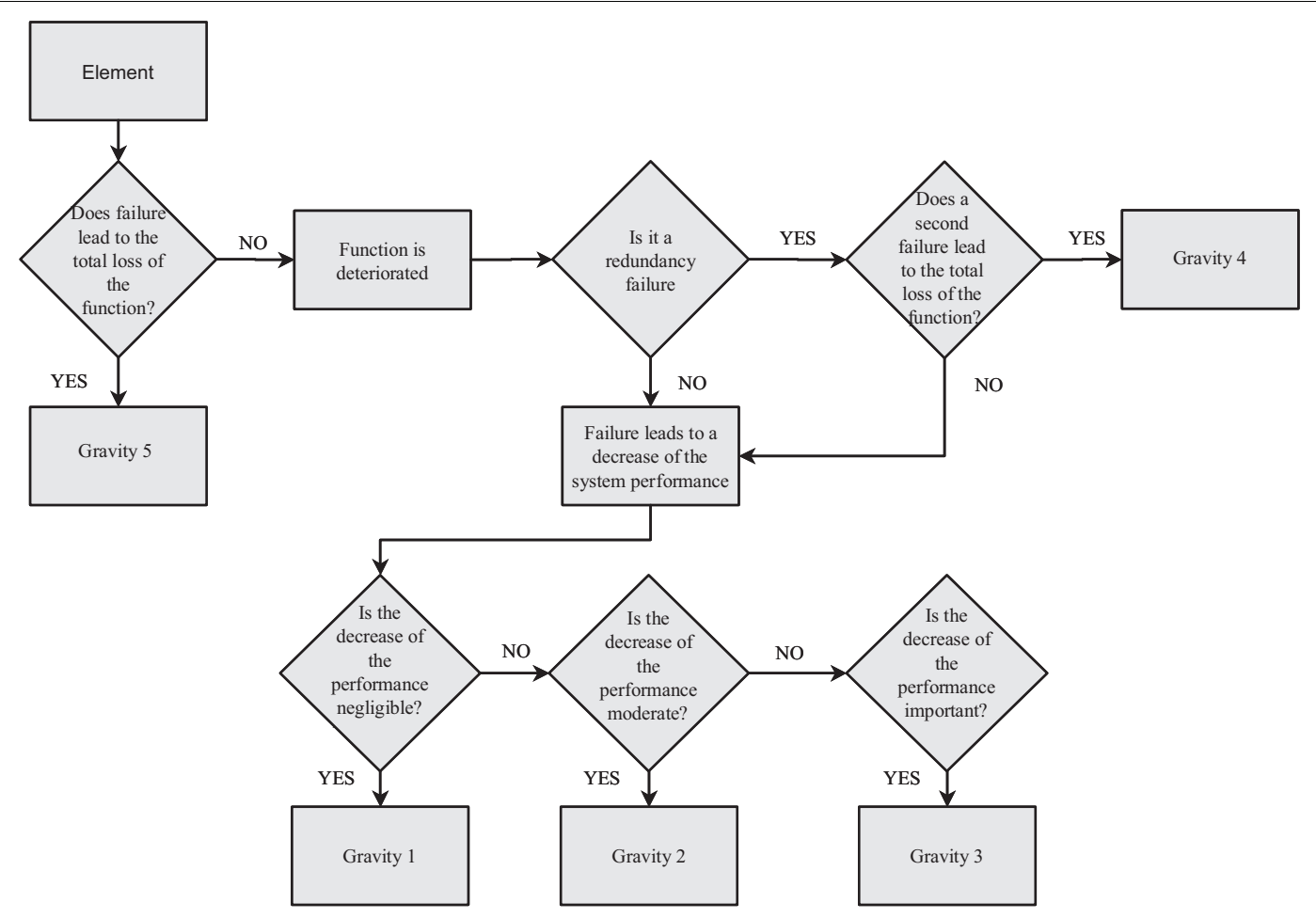


Figure 3 Graph of risk associated with a supply

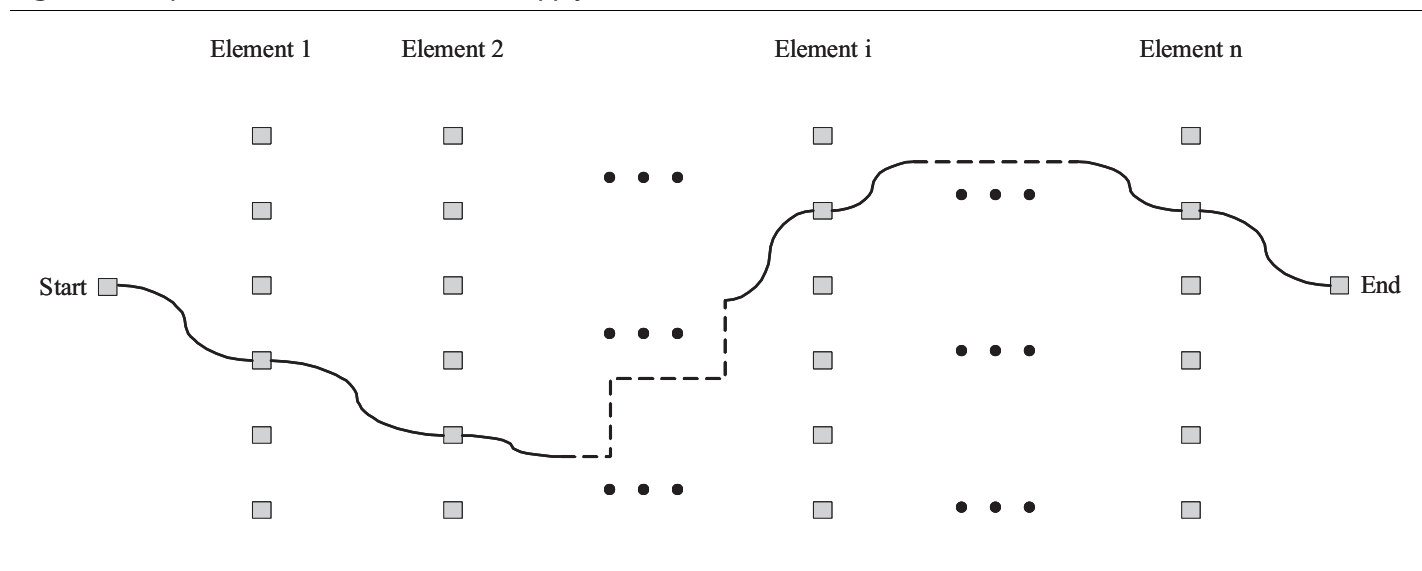

vector concerning a supply strategy

$X_{k}=\left[X_{k, 1}, \ldots, X_{k, i}, \ldots, X_{k, n}\right]$. The length of the circuit associated with this solution is:

$$
R\left(\bar{X}_{k}\right)=\sum_{i=1}^{n} R\left(\bar{X}_{k_{i}}\right)
$$

The problem $(\mathrm{P})$ then consists in identifying the shortest path in the graph $G$ respecting at all times the constraint $\mathrm{B}$.

\subsubsection{Resolution}

The chosen objective function, that is the function of risk $\mathrm{R}\left(X_{k}\right)$, is decomposable which permits the use of dynamic programming. The Bellman theory indicates in such cases that each partial solution belonging to the complete solution is an optimal solution of the partial problem. The general idea is to reduce the preceding problem, having $\mathrm{n}$ variables, to a series of simpler problems. The optimisation is then managed in a recurring manner. It is then possible to calculate the reduction of the maximum risk expected by allowing a budget $\mathrm{E}$ only for the first element considered, represented by $b_{1}(\mathrm{E})$ :

$$
\begin{gathered}
b_{1}(E)=\mathrm{R}\left(X_{1}\right) \\
\text { avec } X_{1}=\frac{E}{C_{1}}
\end{gathered}
$$

Let us suppose, in considering the i first elements, that the maximum reduction of risk is known. Let us call Smax the representation of the maximum stock previously envisaged. From the relation of the recurrence of the dynamic programming, we know, then, how to calculate the reduction of the maximum risk which would result from the distribution of $E$ over the $i+1$ elements.

$$
\begin{aligned}
b_{i+1}(E)= & \min _{0 \leq X_{i+1} \leq \min }\left(s_{\max \times \frac{E}{C_{i+1}}}\right)\left(R\left(\bar{X}_{i+1}\right)\right. \\
& \left.+b_{i}\left(E-C_{i+1} \cdot X_{i+1}\right)\right)
\end{aligned}
$$

We can then calculate $b_{n}(E)$ with $0 \leq E \leq B$ and then know, in particular, the optimal strategy for $E=B$. The method used requires the storing of intermediate values for the determination of the optimal supply strategy. The space of the states of the problem being given by the possible values of the budget, it is clear that the complexity of the calculation and the size of the space in memory are a direct function of the cardinality of this space. In practice, the number of possible states for $\mathrm{E}$ depends on the values of costs $\mathrm{C}_{\mathrm{i}}$. The problem which we treat in this work is such that the number of elements supplied is approximately 70 . Their costs range from several thousand to several million Euros and each element is likely to have up to 5 spare parts. We have artificially limited the number of classes of costs so that the resolution time would remain reasonable, and so that we could obtain an optimal solution representing a base for discussion. It is necessary to carefully establish a compromise between the number of necessary cost classes and the duration of the calculations.

\section{Application to the Columbus Laboratory}

3.1. Description of the Columbus Lab

The International Space Station recently became a reality with the successful launching 
and docking of its first two modules. Europe actively participates in this technological and scientific development by building many elements and in particular, the orbital Columbus laboratory (Cf. Figure 4).

The laboratory is a pressurized habitable module designed to provide for 10 years a multifunction laboratory able to welcome all the fields related to micro gravity: technological and scientific research as well as industrial applications. The detailed design book of the laboratory is right now under process and the launching of the laboratory is scheduled for October 2002.

The average availability objective for the laboratory functions can differ depending on whether it concerns security functions (99.9 per cent of 90 days during 10 years) or operation functions ( 94 per cent of 90 days during 10 years). The achievement of this objective is supported by maintenance activities and in this perspective the laboratory carries about 300 replaceable elements representing 65 different types. Only 15 per cent of these elements are subject to preventive maintenance, which emphasizes the role of the logistic support system. The available supply budget is very limited: approximately 20 million Euros are available for the initial supply and a supplementary 45 million Euros must cover the needs for the whole of the operational phase.

\subsection{Implementing the model}

\subsubsection{Setting up the data}

In order to implement the model, we must first determine the basic data of each element $\mathrm{E}_{1}$ of the laboratory. We still assume that supply is immediate and we use eqs 3 as the base of calculation for the probability of the unavailability of an element. The analysis takes place during the preliminary design phase, the availability and the reliability of the data are not yet ensured. The availability of the data is a recurrent problem when doing Analyses of Logistic Support. However, the method that we propose is based on a comparison between the industrial proposition and the preferences expressed by the user. This comparison is made on common bases: for an equal budget and for the same elements, optimisation suggests the distribution which minimizes the risks associated with differed requests. Furthermore, the method presented does not presume to propose directly an applicable strategy but can be used to focus on the differences with respect to the user preferences. In spite of the limitations of data availability, the method gives an interesting

Figure 4 The international space station and the Columbus laboratory

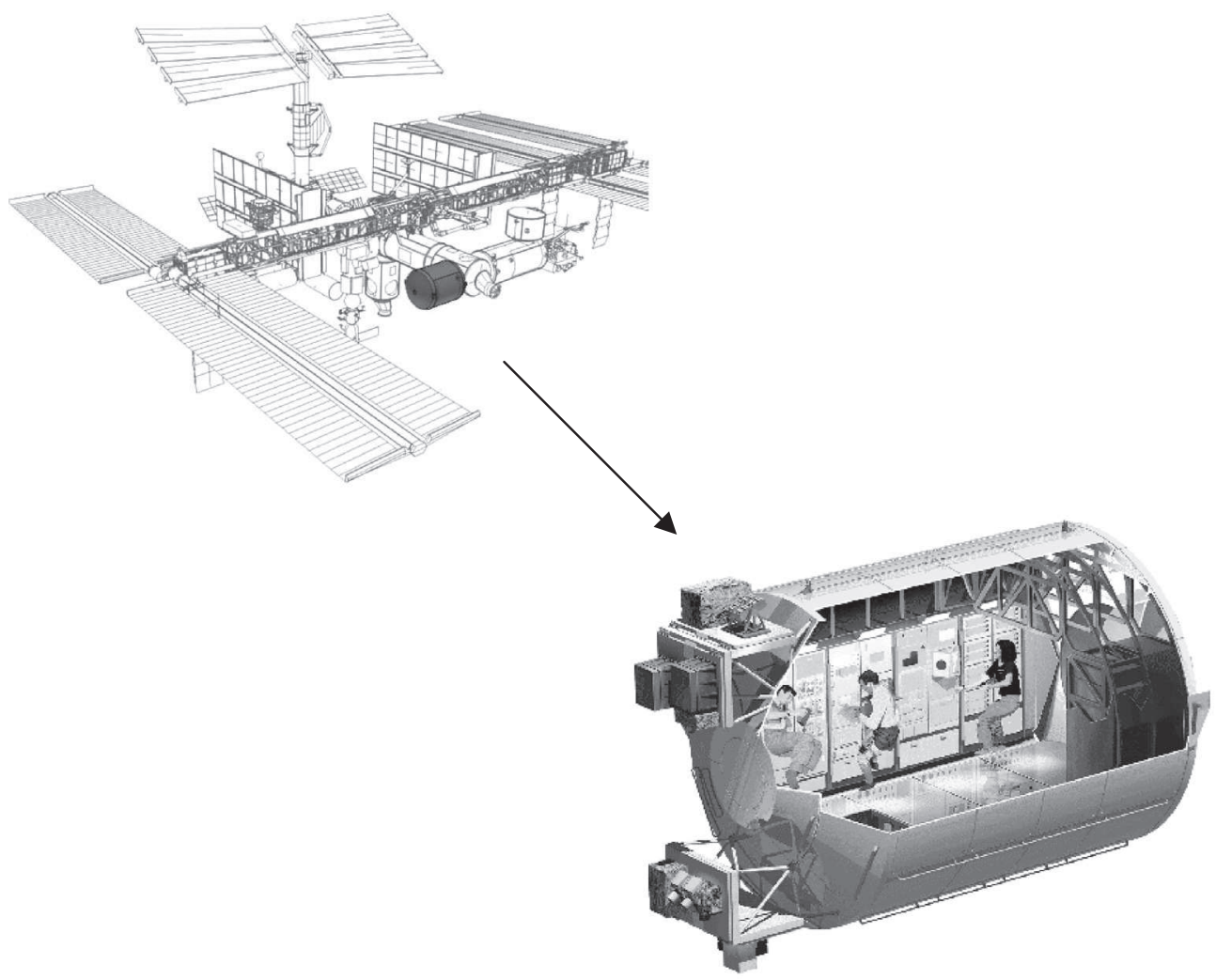


perspective in terms of preparation for negotiation.

\subsubsection{Resolution}

When the basic data are available, the model may be used with the goal of defining, under budget constraints, the nature and the quantity of spare parts required in order to reduce the risk of postponement of a maintenance task. Let us take an example deliberately limited in size to explain the functioning of the optimal distribution of available budget. In order to do this we consider the first two elements of the data base and an available budget of 300,000 Euros. The resolution of equation (1) permits the calculation of the risk associated with each level of stock (Cf. Table II). The cost of each element suggests that the maximum stock must not exceed the value of 2 .

We can then determine the minimum risk if we only consider the purchase of element 1 . It is obvious that this corresponds to the purchase of the maximum number of elements permitted by the budget, that is $\mathrm{X}_{1}=2$ :

$$
b_{1}(300)=\min \left\{\begin{array}{l}
R\left(\bar{X}_{1}\right)=0 \\
R\left(\bar{X}_{1}\right)=1 \\
R\left(\bar{X}_{1}\right)=2
\end{array}\right.
$$

If we now consider the minimum risk which also allows the purchase of Element 2, we can write:

$b_{2}(300)=\min \left\{\begin{array}{l}R\left(\bar{X}_{2}\right)=0+b_{1}(300) \\ R\left(\bar{X}_{2}\right)=1+b_{1}\left(300-C_{2}\right) \\ R\left(\bar{X}_{2}\right)=2+b_{1}\left(300-2 . C_{2}\right)\end{array}\right.$

The distribution giving the minimum risk is then chosen after comparing the results (Cf. Table III). In this case, we choose to purchase 1 element of each type for a budget of 269,000 Euros.

Solving the complete problem, where we consider all of the elements of the data base, is done according to the same principals. We take the budget proposed in the strategy of the industrials as a constraint. The level of risk is

Table II Values of $\bar{X}_{\mathrm{i}}$

\begin{tabular}{lll}
\hline$X_{i}$ & Element 1 & Element 2 \\
\hline $\mathbf{0}$ & $2,64.10^{-2}$ & $4,34.10^{-2}$ \\
$\mathbf{1}$ & $3,51.10^{-4}$ & $9,58.10^{-4}$ \\
$\mathbf{2}$ & $3,12 \cdot 10^{-6}$ & $1,41.10^{-5}$ \\
\hline
\end{tabular}

Table III Example of identification of the optimal distribution

\begin{tabular}{|c|c|c|c|c|}
\hline$E$ & $b_{1}(E)$ & $X_{1}$ & $b_{2}(E)$ & $x_{2}$ \\
\hline 0 & $\mathrm{R}\left(\bar{X}_{1}=0\right)$ & 0 & $\mathrm{R}\left(\bar{X}_{1}=0\right)+\mathrm{R}\left(\bar{X}_{2}=0\right)$ & 0 \\
\hline . & . & . & . & $\cdot$ \\
\hline . & . & . & . & $\cdot$ \\
\hline 132 & . & . & $\mathrm{R}\left(\bar{X}_{1}=0\right)+\mathrm{R}\left(\bar{X}_{2}=0\right)$ & 1 \\
\hline 137 & $\mathrm{R}\left(\bar{X}_{1}=0\right)$ & 1 & $\mathrm{R}\left(\bar{X}_{1}=0\right)+\mathrm{R}\left(\bar{X}_{2}=0\right)$ & . \\
\hline . & . & . & & $\cdot$ \\
\hline . & . & . & & . \\
\hline 264 & . & . & $\mathrm{R}\left(\bar{X}_{1}=0\right)+\mathrm{R}\left(\bar{X}_{2}=0\right)$ & 2 \\
\hline 269 & . & . & $\mathrm{R}\left(\bar{X}_{1}=0\right)+\mathrm{R}\left(\bar{X}_{2}=0\right)$ & 1 \\
\hline 274 & $\mathrm{R}\left(\bar{X}_{1}=0\right)$ & 2 & $\mathrm{R}\left(\bar{X}_{1}=0\right)+\mathrm{R}\left(\bar{X}_{2}=0\right)$ & 0 \\
\hline . & . & . & . & . \\
\hline 300 & . & . & . & . \\
\hline
\end{tabular}

obtained in the manner explained above. The cost is calculated simply by multiplying the cost per unit by the recommended quantity. The calculation of risk values revealed an obvious reduction $(12 \rightarrow 7)$ for the same initial budget (approx. 13 million Euros) when adopting the optimised strategy. The comparison between the proposals assists in directing the negotiations toward the pinpointed areas of divergence.

This difference can be explained by the fact that the industrials consider the parts repairable on the ground, differing from the approximation made by our model. We note also that the optimised strategy considers the supply of several more parts than do the industrials, judging them to be clearly important and thus indicating an obvious divergence. These results lead to the verification of the levels of gravity used and discussion with the industrials in order to understand why the divergences exist. This will contribute to a rise in the level of coherence in the preferences of those who make the decisions.

\section{Conclusion}

It is clear that a number of analyses remain to be worked out. We have seen that there was a reduction in the level of risk, but the level of residual risk may still not be acceptable. The risk reduction approach that we used, (As Low As Reasonable Possible, ALARP), contains the elements of a response: under a budget constraint, the minimum risk is very close to the one indicated by our strategy. To reduce the level of residual risk, in our framework, means increasing the budget. The 
method that we have proposed has several practical advantages: the highlighting of problems of availability, of validity, and of coherence of data, plus the obtaining of a reasonable point of reference. The improvement of these encouraging results requires the integration of periodic resupply and repair, as well as a better appreciation of the consequence of a failure. These are developments that we envisage as logical follow-up to our work.

\section{References}

Blagov, V., (1993) "Orbital space stations mission control.", Mir space station symposium.

Bream, B. (1993), Renew v3.2 user's manual, maintenance estimation simulation for space station freedom program, Technical report, NASA Lewis Research Center.

Bullington, J. (1995), "A probabilistic tool that aids logistics engineers in the establishment of high confidence repair need- dates at the NASA shuttle logistics depot", in, 6th Space logistics Symposium, pp. 46-53.

Constanzi, B. (1996), SLAM II method for spares modelling, Technical report, NASA.

Desroches, A. (1995), Concepts et Méthodes Probabilistes de Base de la sécurité, Tec \& Doc Lavoisier, Paris.

Dejulio, E. and Furlong, K. (1988), "A simulation program for the analysis of on-orbit space station maintenance and logistics operations", in, 2nd Space Logistics Symposium,

Dejulio, E. and Leet, J. (1988), "Space station synergetic RAM-logistics analysis", in, Annual Reliability and Maintainability Symposium,.

ERNO, (1979), Spacelab supply support plan, Technical report, ERNO.

Grenouilleau, J-C. Modélisation de Politiques d'Approvisionnement en Eléments de Rechange pour le Laboratoire Orbital Colombus PhD thesis Ecole Centrale Paris.

Guide, V. and Srivastava, R. (1997), "Repairable inventory theory: Models and applications", European Journal of Operational Research, 102, pp. 1-20.

Kedad-Sidhoum, S. Résolution de problèmes de partitionnement généralisé par des méthodes d'optimisation globale à base de déplacements stochastiques: application à l'ordonnancement de machines parallèles $\mathrm{PhD}$ thesis Laboratoire Productique - Logistique. Ecole Centrale Paris.

Knezevic, J. (1995a), "Mission success driven space system sparing analysis", in, 6th Space Logistics Symposium, January 22-24.
Knezevic, J. (1995b), "Reliability-driven space logistics demand analysis", in, 6th Space Logistics Symposium, January 22-24.

Kline, R. and Sherbrooke, C. (1991), "Inventory based upon system availability: For the space station freedom", in, 4th. Space Logistics symposium, pp. 353-61.

Kline, R. and Sherbrooke, C. (1993), Estimating spares requirements for space station freedom. using the m-spare model, Technical report, Logistics Management Institute.

Leuttgens, R. and Volp, J. (1998), "Operations planning for the international space station", ESA Bulletin, Vol. 94, pp. 57-63.

Leath, K., et al. (1993), "A comparison of space station utilization and operations planning to historical experience", in, IAF'93, International Astronautics Federation.

McCauley, A. (1997), "Resource and maintenance analysis tool (RMAT) overview", in Technical report, NASA.

Minoux, M. (1983), "Programmation Mathématique", in, Théorie et Algorithmes, Tomes 1 et 2, Dunod, Paris.

Nyen, P. and Digernes, T. (1991), "Columbus logistics simulation model", in, 4th Space Logistics Symposium, pp. 362-9.

Pérès, F. Outils d'analyse de performance pour stratégies de maintenance dans les systèmes de production $\mathrm{PhD}$ thesis Université Bordeaux I.

Passaro, R. et al. (1999) "Columbus spares and support equipment provisioning documentation.", Technical report. Alenia Aerospazio. Divisione Spazio.

Schwaab, D. (1991), "Optimal selection of orbital replacement unit on-orbit spares: A space station system availability model", in, 4th Space Logistics Symposium, 494 pp. -500 .

Sherbrooke, C. (1992), Optimal Inventory Modelling of Systems. Multi-Echelon Techniques, (via UMI Books on Demand) John Wiley \& Sons, Inc.

Shishko, R. (1990), "Messoc, capabilities and results", in, 3rd Space Logistics Symposium, 9 pp.

Sepehry-Fard, M. and Coulthard, M. (1995a), "ILS analysis of the ISSA, background and summary of the mathematical modelling \& failure density distributions pertaining to maintenance timedependent parameters", in, 6th Space Logistics Symposium,.

Sepehry-Fard, M. and Coulthard, M. (1995b), "Application of different statistical techniques in ILS of the ISS alpha", in, 6th Space Logistics Symposium, January 22-24.

Sepehry-Fard, M. and Coulthard, M. (1995C), "ILS analysis of the ISSA, an overview of the maintenance timedependent parameters prediction methods enhancements", in, 6th Space Logistics Symposium, January $22-24$. 